\title{
Properties of maltodextrins and glucose syrups in experiments in vitro and in the diets of laboratory animals, relating to dental health
}

\author{
T. H. Grenby* and M. Mistry \\ Department of Oral Medicine and Pathology, GKT Dental Institute, Guy's Hospital, London SE1 9RT, UK
}

(Received 5 July 1999 - Revised 13 December 1999 - Accepted 26 January 2000)

\begin{abstract}
The objective of the study was to examine the cariogenic potentials of maltodextrins and glucose syrups (two glucose polymers derived from starch) using a range of techniques in vitro and in laboratory animals. The experimental methods used were: (1) measurement of acid production from glucose syrups and maltodextrins by human dental plaque micro-organisms; (2) evaluation of the role salivary $\alpha$-amylase in degrading oligosaccharides (degree of polymerisation $>3$ ) in the glucose polymers, estimating the products by HPLC; (3) assessment of the fermentability of trioses relative to maltose; (4) measurement of dental caries levels in three large-scale studies in laboratory rats fed on diets containing the glucose polymers. It was found that acid production from the glucose polymers increased as their higher saccharide content fell. Salivary $\alpha$-amylase rapidly degraded the oligosaccharides (degree of polymerisation $>3$ ), mainly to maltose and maltotriose. In the presence of oral micro-organisms, maltotriose took longer to ferment than maltose, but by the end of a $2 \mathrm{~h}$ period the total amount of acid produced was the same from both. Incorporated into the diets in solid form, the glucose syrups and maltodextrins were associated with unexpectedly high levels of dental caries. In conclusion, the findings were unforeseen in the light of earlier data that a glucose syrup was less cariogenic than sucrose.
\end{abstract}

Glucose polymers: Cariogenicity: Acidogenicity

\begin{abstract}
Maltodextrins and glucose syrups are major ingredients of many different items of food in Western diets, including infants' milk and foods, soft drinks, sports drinks and energy supplements for use in clinical diabetic practice. They also have wide applications in other types of manufactured foods and drinks. They are starch products, generally derived from wheat, potato or maize starches by enzymic or acid hydrolysis. This process can be controlled to give a range of products containing predictable proportions of glucose (dextrose), maltose, maltotriose, oligosaccharides and polysaccharides. Their dextrose equivalent (DE) is a measure of their reducing power, used to distinguish between maltodextrins and glucose syrups, with those having a $\mathrm{DE}<20$ collectively known as maltodextrins and those having $\mathrm{DE}>20$ classified as glucose syrups, although this division is somewhat arbitrary and flexible. These glucose polymers can be used in food manufacturing in the form of clear syrups, but some of them are also available as spray-dried powders. They generally provide energy but glucose syrups are also used in confectionery and soft drinks etc. on account of their sweet taste.

Comparatively little information has been published on
\end{abstract}

the possible dental effects of maltodextrins and glucose syrups. The output of publications on the cariogenic properties of sugars and other fermentable carbohydrates is vast (e.g. Yudkin, 1972; Department of Health, 1989; Bibby, 1990; Rugg-Gunn, 1993), and the dental properties of starches have also been investigated over many years (e.g. British Nutrition Foundation, 1994, 1999; Grenby, 1997), but definitive information on the cariogenic potential of the major and commercially important hydrolysis products of the starches is lacking.

No significant difference was observed in the caries scores in two strains of laboratory rats fed on solid diets formulated with either sucrose or glucose syrup (Grenby, 1972). When the carbohydates were dissolved in the drinking-water, however, one of the two strains of rats showed a significantly greater incidence of caries on the sucrose than on the glucose syrup regimen (Grenby \& Leer, 1974).

Some of the relatively small amount of work reported on the dental effects of the glucose polymers has focused on their metabolism by dental plaque micro-organisms. There is some doubt over whether a direct relationship can be shown to exist between the amount of plaque developing on

\footnotetext{
Abbreviations: DE, dextrose equivalent; DP, degree of polymerisation.

* Corresponding author: Dr Trevor H. Grenby, fax + 44207955 4455, email trevor.grenby@kcl.ac.uk
} 
the teeth and the extent of dental decay. However, in a group of men living in a closed community (British Antarctic Survey), significant reductions in plaque deposition on the teeth were seen towards the end of the 14-week period on high-energy diets when glucose syrup replaced sucrose as the major source of energy (Fry \& Grenby, 1972). In later studies in groups of subjects eating either conventional sucrose-containing sweets or experimental sweets made with starch hydrolysates instead of sucrose over a $3 \mathrm{~d}$ period, the extent of dental plaque and its carbohydrate content were significantly greater after the sucrose sweets than after the experimental sweets (Grenby et al. 1974).

More recent work has indicated that the oral $\mathrm{pH}$ response to glucose syrups varies according to the composition of the syrups (Edgar \& Dodds, 1985). Some glucose polymers used in clinical practice were tested for their acidogenicity by Moynihan et al. (1966a) and were described as potentially cariogenic, although generally found to be less acidogenic than sucrose when exposed to human dental plaque. In a later publication, no significant differences in acidogenicity were observed between an infant soya milk formula containing glucose syrups and an infant milk containing lactose (Moynihan et al. 1996b). An undefined maltodextrin was included in some blended sweeteners to determine their effects on plaque $\mathrm{pH}$, and its superiority to sucrose as a bulking agent was shown (Steinberg et al. 1996).

These experiments have been confined to a relatively narrow and sometimes poorly defined selection of starch hydrolysates. The range available for use in food and drink products is now very wide, however, encompassing many different types of maltodextrins with DE values varying from $10-180 \mathrm{~g} / \mathrm{kg}$ and glucose syrups with DE from 200 up to $995 \mathrm{~g} / \mathrm{kg}$ (this latter representing virtually complete conversion of starch to dextrose). Due to the high current interest in their nutritional and dental properties, a series of studies was set up to examine the fermentability in vitro and the cariogenicity in laboratory animals of a range of maltodextrins and glucose syrups.

Two other points also needed to be investigated. First, the extent to which the starch derivatives could be hydrolysed to fermentable fragments by salivary amylases. Second, as amylolysis gives rise to maltose and maltotriose but little or no dextrose as end-products, how acidogenic are the trioses? There has been uncertainty over whether they are readily fermentable by oral micro-organisms associated with the dental caries process, but an operon has been identified in Streptococcus mutans that can assist in the metabolism of certain trioses (Russell et al. 1992; Tao et al. 1993).

Four sets of experiments were therefore carried out: (1) incubation of the starch hydrolysates with human dental plaque micro-organisms to investigate the extent to which they could ferment the starch hydrolysates to acids; (2) effects of amylases on the starch hydrolysates, to investigate whether complex, long-chain saccharides could be broken down to fermentable sugars in the limited time they are in the mouth; (3) acid production from maltose and maltotriose by human dental plaque microorganisms. Although a number of common mono- and disaccharides are known to be easily fermentable by dental plaque bacteria, no information was found on whether trisaccharides behaved in the same way. The main triose formed by the amylolytic hydrolysis was therefore subjected to the action on oral micro-organisms, and the acid generated was measured in comparison with that from the common 1:4-glucose dimer, maltose, which is known to be easily fermentable; (4) influence of the starch hydrolysates on caries levels in laboratory rats. As pointed out earlier, data on the cariogenicity of maltodextrins and glucose syrups in laboratory animals were patchy and inconsistent, so three large-scale trials of these materials incorporated in the diets of caries-active laboratory rats were carried out, always comparing them with a sugarstarch diet or standardising the DE of the diets.

\section{Materials and methods}

Details of the sugars and oligosaccharide (degree of polymerisation (DP) $>3$ ) profiles of the starch hydrolysates studied are given in Table 1, as furnished by one of the suppliers of a range of starch hydrolysates sold for use in the food industry (AE Staley Manufacturing Company, Decatur, IL, USA).

\section{Incubation of the starch hydrolysates with human dental plaque micro-organisms}

Acid production from the maltodextrins and glucose syrups described in Table 1 was measured in vitro by incubating them with standardised cultures of human dental plaque micro-organisms for $2 \mathrm{~h}$ and recording the change in $\mathrm{pH}$ and the amount of acid developing by neutralization with $0.05 \mathrm{M}-\mathrm{NaOH}$ in a titroprocessor at $37^{\circ} \mathrm{C}$.

The dental plaque samples were obtained from five

Table 1. Composition of the maltodextrins and glucose syrups $(\mathrm{g} / \mathrm{kg})^{\star}$

\begin{tabular}{|c|c|c|c|c|c|c|c|}
\hline & $\begin{array}{l}\text { Maltodextrin } \\
\text { type } 1\end{array}$ & $\begin{array}{l}\text { Maltodextrin } \\
\text { type } 2\end{array}$ & $\begin{array}{l}\text { Maltodextrin } \\
\text { type } 3\end{array}$ & $\begin{array}{l}\text { Maltodextrin } \\
\text { type } 4\end{array}$ & $\begin{array}{c}\text { Glucose syrup } \\
\text { type } 5\end{array}$ & $\begin{array}{c}\text { Glucose syrup } \\
\text { type } 6\end{array}$ & $\begin{array}{c}\text { Dextrose } \\
\text { monohydrate }\end{array}$ \\
\hline Dextrose equivalent & 10 & 150 & 210 & 300 & 350 & 380 & $>995$ \\
\hline Oligosaccharides (DP $>3$ ) & 994 & 890 & 815 & 740 & 640 & 480 & 0 \\
\hline Triose & 2 & 60 & 100 & 125 & 110 & 160 & 0 \\
\hline Maltose & 1 & 40 & 70 & 105 & 110 & 300 & 0 \\
\hline Dextrose (Glucose) & 3 & 10 & 15 & 30 & 140 & 60 & $>995$ \\
\hline Total triose, maltose and dextrose & 6 & 110 & 185 & 260 & 360 & 520 & $>995$ \\
\hline
\end{tabular}

$\mathrm{DP}$, degree of polymerisation.

${ }^{*}$ Glucose polymers provided by Tunnel Refineries Ltd, Greenwich, London, SE10 OPA, UK. Data on their composition provided by AE Staley Manufacturing Group, Decatur, IL, USA. 
young male subjects aged 18-25 years, using sterile swabs interproximally and brushed gently around the gingival margins, then transferred to $10 \mathrm{ml}$ sterile Todd-Hewitt broth and held overnight at $37^{\circ} \mathrm{C}$. Aliquots of the suspension were then taken to inoculate the media containing the starch hydrolysates. To $10 \mathrm{ml}$ sterile $1 \%$ Peptone-P (Oxoid Ltd, Basingstoke, Hants., UK) P-free low-Ca liquid microbiological growth medium containing $100 \mathrm{~g}$ starch hydrolysate/l, $1 \mathrm{ml}$ of the shaken inoculum of plaque micro-organisms was added. The mixtures were stirred continuously and kept at $37^{\circ} \mathrm{C}$ for $2 \mathrm{~h}$. The $\mathrm{pH}$ was recorded every $2 \mathrm{~min}$, and the total acid production was estimated by titration with $0.05 \mathrm{M}-\mathrm{NaOH}$ in a titroprocessor at the end of the incubation period. All the samples were tested simultaneously with the same suspension of inoculum. The controls, which were always run simultaneously, were dextrose (positive) and water (negative).

\section{Effects of amylases on the starch hydrolysates}

To examine the effect of amylolysis of the samples, solutions of the maltodextrins and glucose syrups (100 g/l) in PBS (0.005 M, pH 7.0) were prepared. When the activity of salivary amylase was to be tested, pooled fresh human saliva was filtered through a $0.2 \mu \mathrm{m}$ pore-size filter, and $5.00 \mathrm{ml}$ sterile saliva was added to $40 \mathrm{ml}$ of the solutions. Instead of fresh salivary amylase, other sets of studies were carried out with $20 \mu \mathrm{l}$ hog pancreatic $\alpha$-amylase, activity approximately 200 Units/ml (Boehringer, Mannheim $\mathrm{GmBH}$, Lewes, Sussex, UK). Aliquots $(10 \mathrm{ml})$ were withdrawn at set intervals for analysis. Hydrolysis was stopped by adding $200 \mu \mathrm{l}$ concentrated $\mathrm{HCl}$ (approximately $11.6 \mathrm{M}$ ), and the specimens were stored at $4^{\circ} \mathrm{C}$ if not analysed immediately. Determinations of dextrose, maltose, reducing sugars and total carbohydrate were carried out using standard methods, and a complete carbohydrate profile analysis was made by HPLC.

In the preparation of the sample for HPLC $200 \mathrm{mg}$ Amberlite MBI resin (BDH Ltd, Poole, Dorset, UK) was added to $10 \mathrm{ml}$ of the sample. After agitation for $10 \mathrm{~min}$ the sample was filtered prior to analysis by the Shodex system, with separation of the saccharides by a $\mathrm{K}^{+}$ Phenomenex column (Rezex; Phenomenex Ltd, Macclesfield, Ches., UK), using demineralized distilled water at a flow rate of $0.6 \mathrm{ml} / \mathrm{min}$ as the eluent. The temperature was $85^{\circ} \mathrm{C}$, the injection volume was $30 \mu \mathrm{l}$, and the total run time was $20 \mathrm{~min}$. The saccharides were identified and quantified by a refractive index detector.

\section{Measurement of acid production from maltose and maltotriose by human dental plaque micro-organisms}

Solutions of pure maltose and maltotriose (100 g/l) were subjected to the action of standardised cultures of human dental plaque micro-organisms prepared as described above at $37^{\circ} \mathrm{C}$ for $2 \mathrm{~h}$. The $\mathrm{pH}$ was recorded every $4 \mathrm{~min}$, and total titratable acid was measured at the end of the incubation period, with the data statistically analysed by the $t$ test and signed ranks test (n 3$)$.

\section{Influence of the starch hydrolysates on caries levels in laboratory rats}

Specially-bred litters of rats of the caries-active OsborneMendel strain were divided at weaning (21-24-d-old) into equal-sized groups matched for age, sex and parentage. They were housed two to a stainless-steel grid-floored cage and maintained on the experimental regimens for the next 8 weeks under conditions of controlled temperature, humidity and lighting which were identical for all the regimens.

The animals were examined regularly and weighed weekly. A complete record was kept of food and water intake. At the termination of the experiments dental plaque scores and caries in the mandibular molar teeth were evaluated under $\times 25$ magnification. All the dental examinations were carried out blind. Early lesions were revealed by grinding down the teeth in planes parallel to the occlusal surface. Taking into account both the total number of lesions and their degree of advancement (severity), a caries score was compiled for each animal. Other measurements of caries attack recorded were the total number of lesions, number of gross carious cavities, and the average score per lesion. Diets and drinking water were available to the rats ad libitum. The diets were all in the form of homogeneous dry powders, as all the different types of maltodextrins and glucose syrups evaluated were obtainable as powders or fine crystals (AE Staley Manufacturing Company). The composition of the diets used in the three separate studies are shown in Tables 2, 3 and 4, (Expt 1, six males and six females in each group; Expts 2 and 3, eight males and eight females in each group; all groups perfectly matched for age, sex and litter. In Expt 1 all the diets had a sugar content of $70 \mathrm{~g} / \mathrm{kg}$ or a DE of 7 (Table 2). The intention in Expt 2 was to compare a sugarfree diet (diet E) with diets containing 90 or $180 \mathrm{~g}$ sugar/kg supplied either by glucose polymers (diets F and $\mathrm{G}$ ) or by a grade of dextrose prepared by the complete hydrolysis of starch (diets $\mathrm{H}$ and $\mathrm{J}$, made with dextrose monohydrate, $995 \mathrm{~g}$ dextrose $/ \mathrm{kg}$ (see final column, Table 1). In Expt 3 (see Table 4 for details of composition of diets) two different sugars, dextrose and sucrose, were tested at $180 \mathrm{~g} /$ $\mathrm{kg}$ in diets $\mathrm{M}$ and $\mathrm{N}$, and these were compared with diets $\mathrm{K}$

Table 2. Laboratory rat experiment 1: Composition of diets $(\mathrm{g} / \mathrm{kg})^{*}$

\begin{tabular}{|c|c|c|c|c|}
\hline & $\begin{array}{c}\text { Diet } \\
\text { A }\end{array}$ & $\begin{array}{c}\text { Diet } \\
\text { B }\end{array}$ & $\begin{array}{c}\text { Diet } \\
\text { C }\end{array}$ & $\begin{array}{c}\text { Diet } \\
\text { D }\end{array}$ \\
\hline $\begin{array}{l}\text { Dextrose (from glucose syrup type } 5) \dagger \\
\text { DE (omitting DE of flour) }(\mathrm{g} / \mathrm{kg}) \dagger \\
\text { Ingredients } \\
\text { Dried glucose syrup type } 5 \ddagger \S \\
\text { Maltodextrin type } 2 \ddagger \| \\
\text { Lactose } \\
\text { Sucrose } \\
\text { White flour }\end{array}$ & 157.5 & $\begin{array}{r}70 \\
500\end{array}$ & $\begin{array}{c}70 \\
587.5\end{array}$ & $\begin{array}{c}70 \\
587.5\end{array}$ \\
\hline $\begin{array}{l}\text { DE, dextrose equivalents; DP, degree of poly } \\
\text { * All diets contained (g/kg): skimmed milk pow } \\
20 ; \text { vitamin-mineral-essential fatty acid mi } \\
\text { † Values for dextrose and dextrose equive } \\
\text { calculated from the composition data in Ta } \\
\text { † Supplied by Tunnel Refineries, Greenwich, } \\
\$ 640 \mathrm{~g} \text { oligosaccharides } \mathrm{DP}>3 / \mathrm{kg} \text {. } \\
\text { || } 890 \mathrm{~g} \text { oligosaccharides } \mathrm{DP}>3 / \mathrm{kg} \text {. }\end{array}$ & $\begin{array}{l}\text { ymerisati } \\
\text { der } 320 \text {; } \\
\text { ixture } 2.5 \\
\text { alents in } \\
\text { ible } 1 . \\
\text { UK. }\end{array}$ & $\begin{array}{l}\text { ion. } \\
\text { desiccat } \\
5 . \\
7 \text { diets }\end{array}$ & $\begin{array}{l}\text { A and } \\
\text { tived }\end{array}$ & $\begin{array}{l}\text { owder } \\
\text { were }\end{array}$ \\
\hline
\end{tabular}


Table 3. Laboratory rat experiment 2: Composition of diets $(\mathrm{g} / \mathrm{kg})^{\star}$

\begin{tabular}{|c|c|c|c|c|c|}
\hline & $\begin{array}{c}\text { Diet } \\
\text { E }\end{array}$ & $\begin{array}{c}\text { Diet } \\
\text { F }\end{array}$ & $\begin{array}{c}\text { Diet } \\
\text { G }\end{array}$ & $\begin{array}{c}\text { Diet } \\
\mathrm{H}\end{array}$ & $\begin{array}{c}\text { Diet } \\
\mathrm{J}\end{array}$ \\
\hline Total sugars $\dagger$ & 3 & 180 & 90 & 180 & 90 \\
\hline Maltodextrin type $1 \ddagger \S$ & 500 & & & & \\
\hline Dried glucose syrup type $5 \ddagger \|$ & & 500 & & & \\
\hline Maltodextrin type $3 \ddagger \mathbb{9}$ & & & $486 \cdot 5$ & & \\
\hline Dextrose & & & & 180 & 90 \\
\hline White flour & 157.5 & 157.5 & 171 & 477.5 & $567 \cdot 5$ \\
\hline
\end{tabular}

* All diets contained ( $\mathrm{g} / \mathrm{kg})$ : skimmed milk powder 320; desiccated liver powder 20; vitamin-mineral-essential fatty acids mixture 2.5 .

$\uparrow$ Values for total sugars content were calculated from the glucose syrup and maltodextrin data in Table 1.

‡ Supplied by Tunnel Refineries, Greenwich, London, SE10 OPA, UK.

$\S$ Dextrose equivalent $10 \mathrm{~g} / \mathrm{kg}, 994 \mathrm{~g}$ oligosaccharides (degree of polymerisation $>3) / \mathrm{kg}$.

|| Dextrose equivalent $355 \mathrm{~g} / \mathrm{kg}, 640 \mathrm{~g}$ oligosaccharides (degree of polymerisation $>3) / \mathrm{kg}$.

ๆ Dextrose equivalent $215 \mathrm{~g} / \mathrm{kg}, 815 \mathrm{~g}$ oligosaccharides (degree of polymerisation $>3) / \mathrm{kg}$.

Table 4. Laboratory rat experiment 3: Composition of diets $(\mathrm{g} / \mathrm{kg})^{*}$

\begin{tabular}{|c|c|c|c|c|}
\hline & Diet $\mathrm{K}$ & Diet L & Diet M & Diet $N$ \\
\hline Total sugars $†$ & 180 & 90 & 180 & 180 \\
\hline Glucose syrup type $5 \ddagger \S$ & 500 & & & \\
\hline Maltodextrin type $3 \ddagger \|$ & & $486 \cdot 5$ & & \\
\hline Dextrose & & & 180 & \\
\hline Sucrose (caster sugar) & & & & 180 \\
\hline White flour & $157 \cdot 5$ & 171 & 477.5 & $477 \cdot 5$ \\
\hline \multicolumn{5}{|c|}{$\begin{array}{l}\text { * All diets contained (g/kg): skimmed milk powder } 320 \text {; desiccated liver powder } \\
20 \text {; vitamin-mineral-essential fatty acid mixture } 2 \cdot 5 \mathrm{~g} \text {. } \\
\text { † Values for total sugars were calculated from the glucose syrup and } \\
\text { maltodextrin data in Table } 1 \text {. } \\
\text { † Supplied by Tunnel Refineries, Greenwich, London, SE10 OPA, UK. } \\
\S \text { Dextrose equivalent } 355 \mathrm{~g} / \mathrm{kg}, 640 \mathrm{~g} \text { oligosaccharides (degree of polymer- } \\
\text { isation }>3 \text { ) } / \mathrm{kg} \text {. } \\
\text { || Dextrose equivalent } 215 \mathrm{~g} / \mathrm{kg}, 815 \mathrm{~g} \text { oligosaccharides (degree of polymer- } \\
\text { isation }>3 \text { ) } / \mathrm{kg} \text {. }\end{array}$} \\
\hline
\end{tabular}

and $\mathrm{L}$, in which 180 and $90 \mathrm{~g}$ dextrose/kg were supplied by glucose syrup type 5 and maltodextrin type 3 respectively.

The usual way of evaluating sugar-containing diets for their caries potential is by the use of comparable concentrations of sugars, but for food manufacturers the DE of the starch hydrolysates has more practical significance than the proportion of fermentable saccharides that they contain. This is why the diets in the laboratory rat experiments were formulated with reference to their DE values.

The data were statistically analysed by Student's $t$ test or ANOVA followed by Duncan's multiple-range test, as appropriate.

\section{Results} Incubation of the starch hydrolysates with human dental
plaque micro-organisms

The final $\mathrm{pH}$ values after incubation of the maltodextrins and glucose syrups with standardised cultures of human dental plaque micro-organisms for $2 \mathrm{~h}$ are shown in Fig. 1 . The total acid developing, measured by titration with $0.05 \mathrm{M}-\mathrm{NaOH}$, followed the same trend: maltodextrin $(890 \mathrm{~g}$ oligosaccharides $(\mathrm{DP}>3) / \mathrm{kg})<$ maltodextrin
$(815 \mathrm{~g}$ oligosaccharides $(\mathrm{DP}>3) / \mathrm{kg})<$ maltodextrin $(740 \mathrm{~g}$ oligosaccharides $(\mathrm{DP}>3) / \mathrm{kg})<$ glucose syrup $(640 \mathrm{~g}$ oligosaccharides $(\mathrm{DP}>3) / \mathrm{kg})<$ glucose syrup (480 g oligosaccharides (DP $>3) / \mathrm{kg}$ ). There was a significant difference in the final $\mathrm{pH}$ value of the maltodextrin type 2 (890 g oligosaccharides (DP $>3$ )/kg) compared with the two glucose syrups (640 and $480 \mathrm{~g}$ oligosaccharides $(\mathrm{DP}>3) / \mathrm{kg}$ ).

\section{Effects of amylases on the starch hydrolysates}

After being subjected to amylolytic hydrolysis, maltodextrin type $2(890 \mathrm{~g}$ oligosaccharides (DP $>3) / \mathrm{kg}$ ) showed the highest acid production, according to both $\mathrm{pH}$ and titration data (final $\mathrm{pH} 5.9$ ), compared with $\mathrm{pH} 6 \cdot 1$ and 6.2 for maltodextrins types 3 and 4 (815 and 740 g oligosaccharides $(\mathrm{DP}>3) / \mathrm{kg})$ respectively.

The results of the analysis by HPLC of the product after subjecting the glucose polymers to the action of $\alpha$-amylase, are summarised in Table 5. Amylolysis took place very quickly: the timescale, as shown in Table 5, was only $5 \mathrm{~min}$, and the main changes were observed within the first 2 min. No matter what the initial oligosaccharides DP $>3$ content of the five different starch hydrolysates were, they all fell rapidly to levels in the range of 380 to $480 \mathrm{~g} / \mathrm{kg}$. The results showed that as the levels of oligosaccharides (DP > 3) declined, both triose and maltose levels rose, but the maltose values were the more consistent, averaging $250-300 \mathrm{~g} / \mathrm{kg}$ total carbohydrate after $5 \mathrm{~min}$ exposure to the action of salivary $\alpha$-amylase, despite the widely differing initial values that can be seen in Table 1. Dextrose values remained virtually unaffected by amylolysis, as maltose and maltotriose, rather than dextrose, are endproducts of the attack on the glucose polymers by $\alpha$ amylase.

\section{Acid production from maltose and maltotriose by human dental plaque micro-organisms}

The results of the comparisons of maltose and maltotriose as carbohydrate sources for the metabolism of human dental plaque are shown in Fig. 2. Both the di- and trisaccharides were found to be fermentable by the plaque micro-organisms (difference in final acid production between the two was not significant). The rate of fermentation (Fig. 2) was significantly faster in the maltose than the maltotriose medium during the first $115 \min (P<$ 0.05 ) but by the end of the full 120 min incubation period the difference in rate between them was not significant.

\section{Influence of starch hydrolysates on caries levels in laboratory rats}

In Expt 1 all the diets had a sugar content of $70 \mathrm{~g} / \mathrm{kg}$ or a DE of 7 (see Table 2). The average food intake figures are given in Table 6, from which it can be seen that the rats on diets $\mathrm{C}$ and $\mathrm{D}$, containing lactose and sucrose respectively, ate significantly more of the diets than those on the glucose syrup and maltodextrin diets, A and B. Water intake values showed less variation but tended to be greater on the sugar than on the glucose polymer regimens. Mean weight gains 


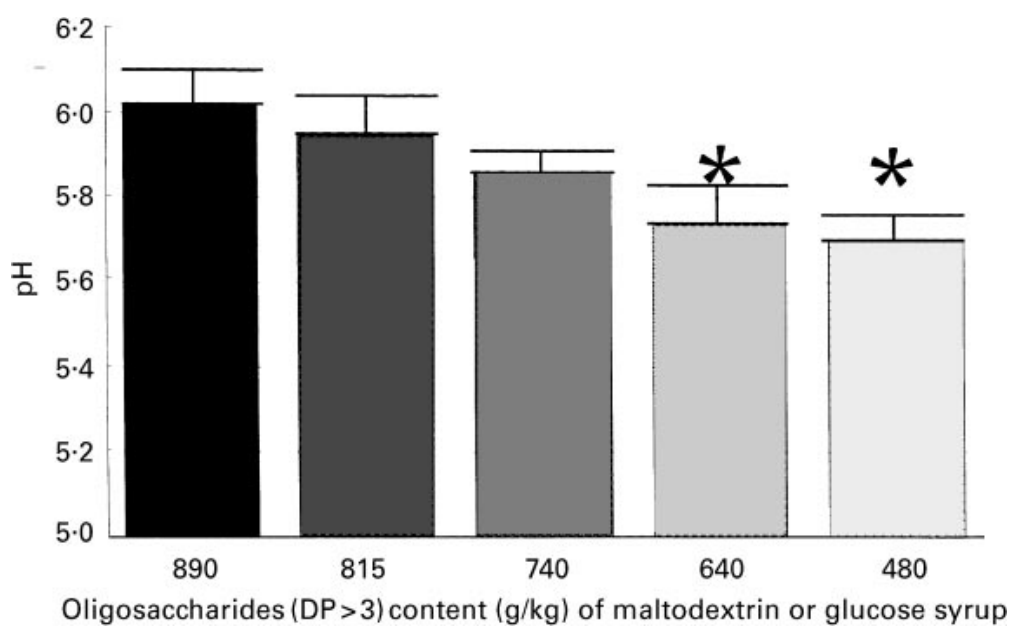

Fig. 1. Mean $\mathrm{pH}$ values after incubation for $2 \mathrm{~h}$ of the glucose polymers (with varying content of oligosaccharides) with human dental plaque micro-organisms. For details of procedures see p. 567. Values are means for five subjects with standard errors represented by vertical bars. DP, degree of polymerisation. Mean values were significantly different from that of the maltodextrin or glucose syrup containing $890 \mathrm{~g}$ oligosaccharide (DP $>3$ ) $/ \mathrm{kg}$ : ${ }^{*} P<0.05$.

followed a similar pattern with animals on the two sugar regimens, $\mathrm{C}$ and $\mathrm{D}$, putting on significantly more weight over the 8-week experimental period than those on the glucose polymer regimens, A and B. The dental findings of Expt 1 are given in Table 7. The two sugar regimens were associated with significantly higher plaque scores than the two glucose polymer regimens $(P<0.05)$, but all the measures of caries showed significantly and consistently higher caries levels on the glucose syrups and maltodextrin regimens than on the lactose-flour and sucrose-flour

Table 5. Summary of the effects of salivary amylase on the composition of starch hydrolysates types 2 to $6(\mathrm{~g} / \mathrm{kg})^{*}$

\begin{tabular}{|c|c|c|c|c|c|}
\hline Glucose polymer & $\begin{array}{l}\text { Incubation } \\
\text { time (min) }\end{array}$ & $\begin{array}{l}\text { Oligosaccharides } \\
\qquad(\mathrm{DP}>3)\end{array}$ & Trioses & Maltose & Dextrose \\
\hline Change (\%) & $\begin{array}{l}0 \\
1 \\
2 \\
5\end{array}$ & $\begin{array}{r}990 \\
730 \\
540 \\
410 \\
-58\end{array}$ & $\begin{array}{r}0 \\
160 \\
310 \\
320 \\
32\end{array}$ & $\begin{array}{r}0 \\
90 \\
150 \\
270 \\
27\end{array}$ & $\begin{array}{r}0 \\
10 \\
10 \\
10\end{array}$ \\
\hline $\begin{array}{l}\text { Type } 3 \\
\text { Change (\%) }\end{array}$ & $\begin{array}{l}0 \\
1 \\
2 \\
5\end{array}$ & $\begin{array}{r}820 \\
660 \\
580 \\
440 \\
-38\end{array}$ & $\begin{array}{r}90 \\
190 \\
240 \\
300 \\
21\end{array}$ & $\begin{array}{r}70 \\
120 \\
170 \\
240 \\
17\end{array}$ & $\begin{array}{l}10 \\
10 \\
10 \\
20\end{array}$ \\
\hline Change (\%) & $\begin{array}{l}0 \\
1 \\
2 \\
5\end{array}$ & $\begin{array}{r}720 \\
560 \\
420 \\
420 \\
-30\end{array}$ & $\begin{array}{r}110 \\
220 \\
320 \\
280 \\
17\end{array}$ & $\begin{array}{r}110 \\
180 \\
210 \\
250 \\
14\end{array}$ & $\begin{array}{l}30 \\
30 \\
30 \\
30\end{array}$ \\
\hline Change (\%) & $\begin{array}{l}0 \\
1 \\
2 \\
5\end{array}$ & $\begin{array}{r}690 \\
570 \\
500 \\
380 \\
-31\end{array}$ & $\begin{array}{r}90 \\
170 \\
200 \\
220 \\
13\end{array}$ & $\begin{array}{r}100 \\
170 \\
200 \\
280 \\
18\end{array}$ & $\begin{array}{l}100 \\
100 \\
100 \\
120\end{array}$ \\
\hline Change (\%) & $\begin{array}{l}0 \\
1 \\
2 \\
5\end{array}$ & $\begin{array}{r}590 \\
540 \\
530 \\
480 \\
-10\end{array}$ & $\begin{array}{r}110 \\
140 \\
150 \\
160 \\
5\end{array}$ & $\begin{array}{r}230 \\
250 \\
270 \\
310 \\
8\end{array}$ & $\begin{array}{l}70 \\
70 \\
70 \\
80\end{array}$ \\
\hline
\end{tabular}

$\mathrm{DP}$, degree of polymerisation.

* For details of procedures see p. 566. 


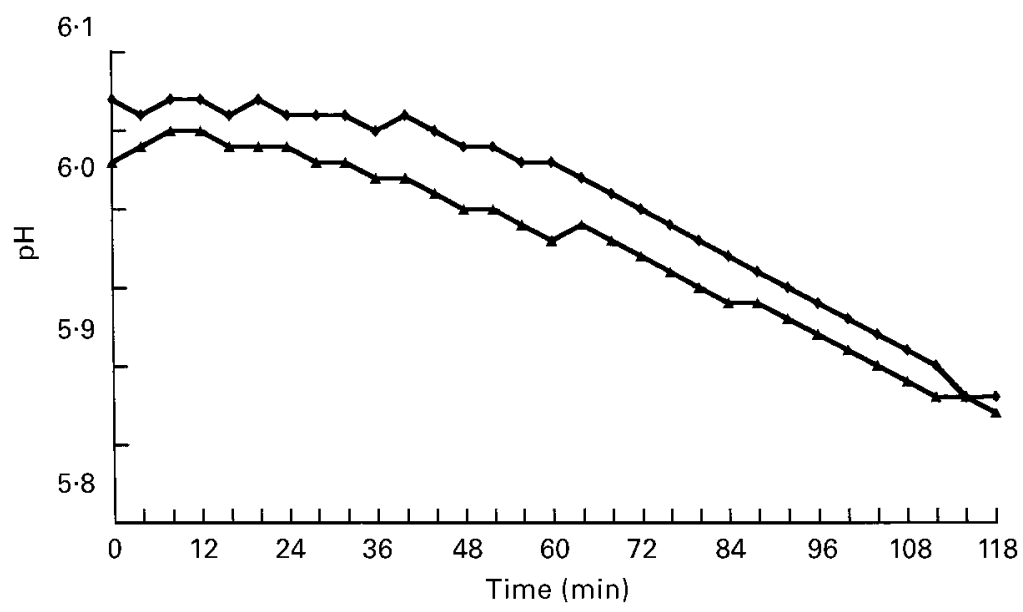

Fig. 2. Total titratable acidity of solutions of $(\mathbf{\Delta})$, maltose $(100 \mathrm{~g} / \mathrm{l} \mathrm{PBS})$ and $(\boldsymbol{\vee})$, maltotriose (100 g/l PBS) incubated with standardised cultures of human dental plaque micro-organisms for $2 \mathrm{~h}$. For details of procedures see p. 567 . Values are means of three incubations. Mean values were significantly different between the two media at $0-112 \mathrm{~min}: P<0.05$. Mean values at $115-120 \mathrm{~min}$ were not significantly different.

Table 6. Food intakes in rats fed on different types of maltodextrins and glucose syrups for 8 weeks ( $g /$ rat per $d$ )

(Mean values)

\begin{tabular}{|c|c|c|c|c|}
\hline & \multirow[b]{2}{*}{ Diet* } & \multirow[b]{2}{*}{$n$} & \multicolumn{2}{|c|}{ Week } \\
\hline & & & 1 & 8 \\
\hline \multicolumn{5}{|l|}{ Expt 1} \\
\hline Males & A & 6 & $7 \cdot 7$ & $16 \cdot 8$ \\
\hline Males & B & 6 & $6 \cdot 3$ & $14 \cdot 0$ \\
\hline Males & C & 6 & $7 \cdot 7$ & $32 \cdot 2$ \\
\hline Males & D & 6 & $7 \cdot 7$ & $25 \cdot 9$ \\
\hline Females & A & 6 & 8.4 & $15 \cdot 4$ \\
\hline Females & B & 6 & 8.4 & $14 \cdot 0$ \\
\hline Females & C & 6 & $9 \cdot 1$ & 24.5 \\
\hline Females & D & 6 & $7 \cdot 7$ & $22 \cdot 4$ \\
\hline \multicolumn{5}{|l|}{ Expt 2} \\
\hline Males & $E$ & 8 & $4 \cdot 2$ & $9 \cdot 8$ \\
\hline Males & $\mathrm{F}$ & 8 & 4.2 & $9 \cdot 8$ \\
\hline Males & $\mathrm{G}$ & 8 & $5 \cdot 6$ & 11.2 \\
\hline Males & $\mathrm{H}$ & 8 & 4.9 & $11 \cdot 2$ \\
\hline Males & $\mathrm{J}$ & 8 & 4.9 & $14 \cdot 0$ \\
\hline Females & $E$ & 8 & 3.5 & $9 \cdot 1$ \\
\hline Females & $\mathrm{F}$ & 8 & 4.2 & 8.4 \\
\hline Females & G & 8 & 4.2 & $9 \cdot 8$ \\
\hline Females & $\mathrm{H}$ & 8 & 4.2 & $10 \cdot 5$ \\
\hline Females & $\mathrm{J}$ & 8 & 4.9 & $10 \cdot 5$ \\
\hline \multicolumn{5}{|l|}{ Expt 3} \\
\hline Males & $\mathrm{K}$ & 8 & 8.4 & $15 \cdot 4$ \\
\hline Males & $\mathrm{L}$ & 8 & 8.4 & $16 \cdot 8$ \\
\hline Males & M & 8 & $9 \cdot 1$ & $22 \cdot 4$ \\
\hline Males & $\mathrm{N}$ & 8 & $9 \cdot 1$ & $18 \cdot 9$ \\
\hline Females & $\mathrm{K}$ & 8 & $7 \cdot 7$ & 11.2 \\
\hline Females & L & 8 & 8.4 & $15 \cdot 4$ \\
\hline Females & M & 8 & 9.1 & $16 \cdot 8$ \\
\hline Females & $\mathrm{N}$ & 8 & 9.1 & 18.9 \\
\hline
\end{tabular}

${ }^{*}$ For details of diets see Table 2 (Expt 1), Table 3 (Expt 2) and Table 4 (Expt 3). regimens, with $P$ always $<0 \cdot 05$. The average caries score per lesion was significantly higher on the maltodextrin than on the glucose syrup regimen (Table $7, P<0 \cdot 05$ ).

Details of the five diets evaluated in Expt 2 are given in Table 3. The sources of the glucose polymers for diets $F$ and $\mathrm{G}$ were glucose syrup type 5 and maltodextrin type 3 (AE Staley Manufacturing Company; see Table 1) respectively. The food and water intake figures were similar in all five groups (food, see Table 6; water, males 18.4 and females $18.1 \mathrm{ml} /$ rat per day) but the overall food intake was consistently higher on diet $\mathrm{J}$ (90 g dextrose $/ \mathrm{kg}$ ) than on the other regimens. The differences in mean weight gains between the regimens were generally small, but both males and females grew quickest on the $90 \mathrm{~g}$ dextrose $/ \mathrm{kg}$ diet $\mathbf{J}$ and slowest on the very-low-sugar diet $\mathrm{E}$. The dental data are presented in Table 8 . The plaque scores were significantly lower on the glucose syrup regimen $\mathrm{F}$ than on any of the other regimens. Regime $\mathrm{G}(90 \mathrm{~g}$ dextrose $/ \mathrm{kg}$ supplied by maltodextrin type 3 ) produced significantly lower plaque scores than the low-dextrose regimen $\mathrm{E}$ and the 90 and $180 \mathrm{~g}$ dextrose/ $\mathrm{kg}$ regimens $\mathrm{H}$ and $\mathrm{J}$. The caries data showed the reverse, with significantly higher caries values on the glucose syrup and maltodextrin diets F and G, than on the dextrose diets $\mathrm{H}$ and $\mathrm{J}$ and on the very lowdextrose diet $\mathrm{E}$. These findings were based on analyses of the caries scores and average total number of lesions. Average dental caries scores per lesion were all very low and showed no significant differences between the regimens.

In laboratory rat Expt 3 (for details of composition of diets see Table 4) average food intake figures are given in Table 6, from which it can be seen that consumption of the two $180 \mathrm{~g}$ pure sugar/ $\mathrm{kg}$ diets $\mathrm{M}$ and $\mathrm{N}$ was higher than that of diets $\mathrm{K}$ and $\mathrm{L}$, in which the 90 or $180 \mathrm{~g}$ of sugars $/ \mathrm{kg}$ diet were supplied by a maltodextrin and a glucose syrup respectively. Average weight gains followed the same 
Table 7. Rat experiment 1: Summary of dental data

(Mean values with standard errors for twelve rats per group)

\begin{tabular}{|c|c|c|c|c|c|c|c|c|c|}
\hline \multirow{2}{*}{$\begin{array}{l}\text { Diet }^{\star} . . \\
\text { Dental scorest }\end{array}$} & \multicolumn{2}{|c|}{ A } & \multicolumn{2}{|c|}{ B } & \multicolumn{2}{|c|}{ C } & \multicolumn{2}{|c|}{$\mathrm{D}$} & \multirow{2}{*}{$\begin{array}{l}\text { Inter-group differences } \\
\text { at } P<0.05\end{array}$} \\
\hline & Mean & SE & Mean & SE & Mean & SE & Mean & SE & \\
\hline Dental plaque scores & 5.4 & 0.4 & $6 \cdot 5$ & $0 \cdot 7$ & $12 \cdot 8$ & $0 \cdot 8$ & $13 \cdot 5$ & 0.7 & $\begin{array}{l}A \text { and } B \text { scores significantly } \\
\text { lower than } C \text { and } D \text { scores }\end{array}$ \\
\hline Caries scores & $14 \cdot 7$ & $2 \cdot 1$ & $17 \cdot 5$ & 1.9 & $3 \cdot 7$ & $0 \cdot 6$ & $5 \cdot 0$ & 0.8 & $\begin{array}{l}A \text { and } B \text { scores significantly } \\
\text { higher than } C \text { and } D \text { scores }\end{array}$ \\
\hline Total no. of carious lesions per rat & $9 \cdot 3$ & 0.9 & $9 \cdot 8$ & 0.8 & 3.5 & $0 \cdot 6$ & $4 \cdot 3$ & 0.6 & $\begin{array}{l}A \text { and } B \text { scores significantly } \\
\text { higher than } C \text { and } D \text { scores }\end{array}$ \\
\hline Smooth-surface caries scores & $2 \cdot 7$ & 0.6 & $2 \cdot 8$ & $0 \cdot 7$ & 0.3 & $0 \cdot 2$ & 0.3 & 0.2 & $\begin{array}{l}A \text { and } B \text { scores significantly } \\
\text { higher than } C \text { and } D \text { scores }\end{array}$ \\
\hline No. of gross cavities per rat & 0.7 & 0.3 & $1 \cdot 0$ & 0.3 & 0 & 0 & 0 & 0 & $\begin{array}{l}A \text { and } B \text { scores significantly } \\
\text { higher than } C \text { and } D \text { scores }\end{array}$ \\
\hline Average scores per lesion & 1.5 & $0 \cdot 1$ & $1 \cdot 8$ & $0 \cdot 1$ & 1.0 & 0 & $1 \cdot 1$ & 0.1 & $\begin{array}{l}A \text { and } B \text { scores significantly } \\
\text { higher than } C \text { and } D \text { scores } \\
\text { and B scores significantly } \\
\text { higher than A scores }\end{array}$ \\
\hline
\end{tabular}

* For details of diets see Table 2. Diets were fed for 8 weeks.

$\dagger$ For details of dental examination procedures see p. 567. Rats were of the caries-active Osborne-Mendel Strain.

Table 8. Laboratory rat experiment 2: Summary of dental data

(Mean values with standard errors for sixteen rats per group)

\begin{tabular}{|c|c|c|c|c|c|c|c|c|c|c|c|}
\hline \multirow{2}{*}{$\begin{array}{l}\text { Diet}^{\star} . \\
\text { Dental scores } †\end{array}$} & \multicolumn{2}{|c|}{$E$} & \multicolumn{2}{|c|}{$\mathrm{F}$} & \multicolumn{2}{|c|}{$\mathrm{G}$} & \multicolumn{2}{|c|}{$\mathrm{H}$} & \multicolumn{2}{|c|}{ J } & \multirow[b]{2}{*}{ inter-group differences at $P<0.05$} \\
\hline & Mean & SE & Mean & SE & Mean & SE & Mean & SE & Mean & SE & \\
\hline Plaque scores & $14 \cdot 6$ & 0.5 & 0.8 & 0.8 & $10 \cdot 9$ & 0.8 & 0.5 & 0.5 & 0.4 & 0.4 & $\begin{array}{l}\text { F scores significantly lower than } \\
\mathrm{E}, \mathrm{G}, \mathrm{H} \text { and } \mathrm{J} \text { scores } \\
\text { G scores significantly lower than } \\
\mathrm{E}, \mathrm{H} \text { and } \mathrm{J} \text { scores }\end{array}$ \\
\hline Caries scores & $3 \cdot 4$ & 0.4 & $6 \cdot 4$ & 0.9 & $7 \cdot 0$ & $1 \cdot 3$ & $3 \cdot 8$ & 0.5 & 3.3 & 0.4 & $\begin{array}{l}F \text { and } G \text { scores significantly higher than } \\
E, H \text { and } J \text { scores }\end{array}$ \\
\hline Total no. of carious lesions per rat & $3 \cdot 0$ & 0.3 & 4.5 & 0.4 & $5 \cdot 2$ & 0.6 & 3.4 & 0.3 & $3 \cdot 1$ & 0.3 & $\begin{array}{l}\mathrm{G} \text { scores significantly higher than } \\
\mathrm{E}, \mathrm{H} \text { and } \mathrm{J} \text { scores and } \mathrm{F} \text { scores } \\
\text { significantly higher than } \mathrm{E} \text { and } \mathrm{J} \text { scores }\end{array}$ \\
\hline
\end{tabular}

* For details of diets see Table 3. Diet were fed for 8 weeks.

† For details of dental examination procedures see p. 567. Rats were of the caries-active Osborne-Mendel Strain.

Table 9. Rat experiment 3: Summary of dental data

(Mean values with standard errors for sixteen rats per group)

\begin{tabular}{|c|c|c|c|c|c|c|c|c|c|}
\hline \multirow{2}{*}{$\begin{array}{l}\text { Diet }^{\star} . \\
\text { Dental scores† }\end{array}$} & \multicolumn{2}{|c|}{$\mathrm{K}$} & \multicolumn{2}{|c|}{ L } & \multicolumn{2}{|c|}{ M } & \multicolumn{2}{|c|}{$\mathrm{N}$} & \multirow[b]{2}{*}{ Inter-group differences at $P<0.05$} \\
\hline & Mean & SE & Mean & SE & Mean & SE & Mean & SE & \\
\hline Dental plaque scores & $8 \cdot 3$ & 0.9 & $10 \cdot 9$ & 0.7 & $13 \cdot 7$ & 0.8 & $14 \cdot 4$ & 0.6 & $\begin{array}{l}K \text { and } L \text { scores significantly } \\
\text { lower than } M \text { and } N \text { scores. } \\
\text { K score significantly lower than } L \text { score }\end{array}$ \\
\hline Caries scores & $10 \cdot 5$ & $1 \cdot 0$ & $10 \cdot 3$ & $1 \cdot 2$ & $2 \cdot 9$ & 0.5 & $6 \cdot 1$ & 1.0 & $\begin{array}{l}\mathrm{K} \text { and } \mathrm{L} \text { scores significantly } \\
\text { higher than } \mathrm{M} \text { and } \mathrm{N} \text { scores. } \\
\mathrm{M} \text { score significantly lower than } \mathrm{N} \text { score }\end{array}$ \\
\hline Total no. of lesions per rat & $6 \cdot 2$ & 0.5 & $6 \cdot 0$ & 0.5 & $2 \cdot 6$ & 0.4 & $4 \cdot 0$ & 0.5 & $\begin{array}{l}\mathrm{K} \text { and } \mathrm{L} \text { scores significantly } \\
\text { higher than } \mathrm{M} \text { and } \mathrm{N} \text { scores. } \\
\mathrm{M} \text { score significantly lower than } \mathrm{N} \text { score }\end{array}$ \\
\hline
\end{tabular}

* For details of diets see Table 4. Diets were fed for 8 weeks.

$\dagger$ For details of dental examination procedures see p. 567. Rats were of the caries-active Osborne-Mendel Strain.

pattern, with the final weights averaging $257 \mathrm{~g}$ on diets $\mathrm{M}$ and $\mathrm{N}$ compared with $216 \mathrm{~g}$ on diets $\mathrm{K}$ and $\mathrm{L}$ (males) and $211 \mathrm{~g}$ on diets $\mathrm{M}$ and $\mathrm{N}$ compared with $179 \mathrm{~g}$ on diets $\mathrm{K}$ and $\mathrm{L}$ (females). The mean dental plaque scores are shown in Table 9. There was significantly less plaque on the teeth of the group receiving $180 \mathrm{~g}$ sugar $/ \mathrm{kg}$ provided by glucose syrup than on the teeth of any other group $(P<0.05)$. The group receiving $90 \mathrm{~g}$ of sugar $/ \mathrm{kg}$ from a maltodextrin had intermediate levels of plaque, significantly above that of the glucose syrup but significantly lower than those on the pure sugar regimens $\mathrm{M}$ and $\mathrm{N}$, which were not significantly different. Caries data are given in Table 9, and show no 
significant difference between the effects of the glucose syrup and maltodextrin regimens $\mathrm{K}$ and $\mathrm{L}$, significantly lower scores on the $180 \mathrm{~g}$ sucrose $/ \mathrm{kg}$-flour regimen $\mathrm{N}$, and the scores on the $180 \mathrm{~g}$ dextrose $/ \mathrm{kg}$-flour regimen $\mathrm{M}$, significantly lower again than those on regimen $\mathrm{N}$. The average score per lesion was also recorded and showed the same features as the caries scores and the total numbers of carious lesions.

\section{Discussion}

The first set of studies (p. 567 and Fig. 1) showed the relationship between the composition of the glucose polymers and the acid that could be generated from them by human dental plaque micro-organisms, and it can be seen that the lower the content of oligosaccharides DP $>3$, the greater the acid production. The inference from this is that the higher the proportion of fermentable sugars in the glucose polymers, the greater their cariogenic potential, suggesting that glucose syrups such as types 5 and 6 (Table 1 ), with a relatively high $\mathrm{DE}$ value, could pose more of a risk to human dental health than maltodextrins having a lower DE, e.g. type 1 (Table 1).

Prediction of the dental effects of foods containing glucose polymers is complicated by the wide range of maltodextrins and glucose syrups that can be used. The factor determining their dental effects is not their initial composition or DE value, but their behaviour in the mouth, particularly their susceptibility to attack by salivary $\alpha$ amylases and the rapidity of the release of cariogenic (fermentable) sugars or oligosaccharides. The influence of the concentration of an $\alpha$-amylase on the degradation of starch has been studied by Govindasamy et al. (1997), but the most notable feature of the action of oral $\alpha$-amylases in the work reported here (technique 2, p. 567; Table 5) was its speed. Starting with a set of widely-differing types of glucose polymers with DE values ranging from 15 to 38 , the levels of oligosaccharides DP $>3$ they contained, with initial values of $480-890 \mathrm{~g} / \mathrm{kg}$, fell rapidly within just 2 to $5 \mathrm{~min}$ to approximately $400 \mathrm{~g} / \mathrm{kg}$. The significance of these findings depends on the clearance times from the mouth of foods and drinks containing the glucose polymers. Drinks are thought to be cleared more quickly than solid foods, but from the data shown here it is unlikely that confectionery and other solid foods could be cleared from the mouth before extensive amylolysis has taken place. There has been a belief that amylolysis of higher saccharides is such a slow process that it is unlikely to have a significant effect on the levels of fermentable sugars in the mouths of human subjects, but these findings indicate that amylolysis takes place much more rapidly than was thought, and it may be sufficient to contribute to levels of acid in the mouth which can have an adverse effect on dental health.

As can be seen from Table 5, levels of dextrose, which is not a major product of the hydrolysis of starch by $\alpha$ amylase, remained constant, but both di- and trisaccharide concentrations rose as the oligosaccharides DP $>3$ were hydrolysed. This suggested a rapid increase in the fermentability of the glucose polymers. It was already known that disaccharides such as maltose are easily fermentable to potentially cariogenic acids by oral micro-organisms, but information was lacking on the utilization of trioses as substrates. When this point was investigated by technique 3 (p. 567) it was apparent that maltotriose was fermented to produce as much acid as from maltose by the end of a $2 \mathrm{~h}$ period of incubation (Fig. 2). Although for most of the incubation period the $\mathrm{pH}$ with maltotriose as substrate was significantly higher than with maltose, suggesting that maltose is more readily fermented than maltotriose by human dental plaque micro-organisms; after about $115 \mathrm{~min}$ the position was reversed, and the final $\mathrm{pH}$ was lower in the presence of maltotriose than maltose (Fig. 2; difference at $2 \mathrm{~h}$ not significant).

The data in Table 5 indicate that almost all the disappearance of oligosaccharides (DP $>3$ ) from the glucose polymers can be accounted for by the concurrent rise in di- and trisaccharides, but it is not known if the hydrolysis of starch to maltodextrins and glucose syrups leads to the formation of significant amounts of tetra- and other short-chain oligosaccharides that can be fermented under the same conditions as di- and trisaccharides, and this is a point that needs to be investigated. Although little information is at present available on this matter, Russell et al. (1992) and Tao et al. (1993) have identified the msm operon in Streptococcus mutans that is responsible for the metabolism of melibiose (a disaccharide), raffinose (a trisaccharide) and certain isomaltosaccharides such as isomaltotriose, and they have confirmed that this operon can specify all the cellular components necessary for their transport and initial metabolism.

The remaining matter to be examined was the cariogenicity of the glucose polymers in laboratory animals. It should be noted that in diets formulated with starch hydrolysates such as A, B, E, F, G, K and L, the levels of dextrose oligomers fermentable in the mouth could exceed the levels of sugars in the sugar-flour diets C, D, H, $\mathrm{J}, \mathrm{M}$ and $\mathrm{N}$, making direct comparisons of the caries potentials of the starch hydrolysate and sugar-flour regimens difficult. Although methods exist for controlling the frequency of eating in laboratory animals (e.g. Grenby \& Mistry, 1995), timed feeding was not used in the trials reported here, but food intake was recorded week-by-week (summarised in Tables 6 and 10). In all of the three largescale experiments testing the materials in caries-active laboratory rats, the mean dental plaque scores were significantly higher on the sugar-flour controls than on the glucose syrup and maltodextrin diets (Tables 7, 8 and 9). There was also a suggestion that less plaque was deposited on the teeth of the rats on glucose syrup regimens than on those receiving maltodextrins (Expts 2 and 3 ) but the one anomaly in this was the mean plaque score on diet $\mathrm{E}$ in Expt 2, which contained a maltodextrin and gave results statistically indistinguishable from those on the control regimens $\mathrm{H}$ and $\mathrm{J}$.

The caries data showed the opposite effect. In all three studies in rats, the incidence of caries was consistently and significantly higher on the glucose syrup and maltodextrin diets than on control regimens that were formulated to provide the same dietary levels of mono- and disaccharides (Tables 7, 8 and 9). This was not because food intake was greater on the glucose polymer regimens. It can be seen, for example, from the data in Table 6 that food consumption 
Table 10. Summary of changes in food consumption, body weight and mean caries scores in laboratory rats fed on different types of maltodextrins and glucose syrups for 8 weeks

\begin{tabular}{|c|c|c|c|c|}
\hline Experiment no. $\dagger$ & No. of rats & $\begin{array}{c}\text { Change in } \\
\text { food intake (\%) }\end{array}$ & $\begin{array}{c}\text { Change in } \\
\text { body weight (\%) }\end{array}$ & $\begin{array}{c}\text { Caries } \\
\text { scores }(\%) \ddagger\end{array}$ \\
\hline 1 & 48 & $-74^{*}$ & $-46^{*}$ & $+73^{*}$ \\
\hline 2 & 80 & -18 & -16 & $+37^{\star}$ \\
\hline 3 & 64 & $-29^{\star}$ & $-25^{\star}$ & $+57^{\star}$ \\
\hline
\end{tabular}

,+- , Values were higher or lower respectively for rats fed on the starch hydrolysate-based diets than on control sugar-flour-based diets.

Values were significantly different from those on the control sugar-flour-based diet $\left({ }^{\star} P<0.05\right)$.

† In experiment 1, all the diets had a sugar content of $70 \mathrm{~g} / \mathrm{kg}$ (for details see Table 2); in experiment 2, a sugar-free diet was compared with diets containing 90 or $180 \mathrm{~g}$ sugar $/ \mathrm{kg}$ supplied by either glucose polymers or dextrose monohydrates (for details see Table 3); in experiment 3 , sucrose and dextrosecontaining diets $(180 \mathrm{~g} / \mathrm{kg}$ ) were compared with diets containing glucose syrup type 5 and maltodextrin type 3 (180 and $90 \mathrm{~g} / \mathrm{kg}$ respectively; for details see Table 4).

‡ For details of scoring system see p. 567. Rats were of the caries-active Osbourne-Mendel Strain.

was always greater on the control diets than on the glucose polymer regimens, and this was reflected in the animals' mean weight gains, which were also higher on the sugar diets than on the glucose polymer regimens (for a summary see Table 10). These findings appear to conflict with earlier data that a glucose syrup with DE 41 added to the drinkingwater at $200 \mathrm{~g} / 1$ was significantly less cariogenic than sucrose (Grenby \& Leer, 1974). The diets in Expts 1, 2 and 3 were formulated so as to provide mono- and disaccharide levels or DE values the same as those of the sugar-flour diets $\mathrm{C}, \mathrm{D}, \mathrm{H}, \mathrm{J}, \mathrm{M}$ and $\mathrm{N}$. Apart from the sugars, the control diets contained only white flour, skimmed milk powder and small amounts of desiccated liver powder and vitamin-mineral-essential fatty acid supplement (see Tables 2, 3 and 4), all of which are believed to have a low cariogenic potential. At a dietary level of only $70 \mathrm{~g} / \mathrm{kg}$, both the sugar-flour regimens (diets D and C) showed a uniformly low cariogenic potential in Expt 1 (Table 7).

The overall incidence of caries was also low in animal Expt 2, and no significant difference was observed between the 90 and $180 \mathrm{~g}$ dextrose $/ \mathrm{kg}$ diets $\mathrm{H}$ and $\mathrm{J}$ (Table 8). Earlier studies had suggested that sucrose was more cariogenic than its constituent monosaccharides, dextrose and fructose (e.g. Grenby \& Hutchinson, 1969), so in Expt 3 sucrose and dextrose were tested at the same level of $180 \mathrm{~g} / \mathrm{kg}$ diet ( $\mathrm{N}$ and $\mathrm{M}$ respectively), in comparison with 90 and 180 g mono-, di- and trisaccharides/kg provided by a maltodextrin and a glucose syrup respectively (diets $\mathrm{L}$ and K, Table 4). This showed the difference in cariogenicity between the two sugars that had been noted before, with significantly higher caries levels on the sucrose than on the dextrose regimen (diets $\mathrm{N}$ and $\mathrm{M}$ respectively, Table 9 ). The caries figures were uniformly and significantly higher, however, on both of the glucose polymer regimens, no matter whether they provided 90 or $180 \mathrm{~g}$ total dextrose, maltose and triose $/ \mathrm{kg}$ diet. This raises the possibility that the glucose polymers may have contained fermentable sugars other than mono-, di- and trisaccharides. The composition figures in Table 1 include all glucose oligomers apart from those under the collective grouping of 'oligosaccharides (DP $>3$ )'. At present little is known about the cariogenic potential of the glucose polymers, and at what specific chain-length they cease to be easily fermentable by-oral micro-organisms. The next stage of this work should be to investigate this point further and to determine their potential cariogenicity.

Some other features of the glucose polymers that have not been examined fully are their physical properties. They are available in a variety of forms ranging from liquids to agglomerates and powders. Those used in laboratory rat Expts 1, 2 and 3 were all in the form of powders, but when they are converted or partially converted into liquids in the mouth the viscosity of the resulting solutions needs to be taken into account. The importance of oral clearance time and the effect of gelatinizing starch were pointed out by Brudevold et al. (1988). Glucose syrups can have a comparatively high viscosity which could of course impede clearance from the mouth, with the inference that a longer retention time could contribute to the unexpected relatively high cariogenicity of the glucose syrups and maltodextrins.

It is not straightforward to make direct extrapolations from laboratory data to human nutrition and dental health, but apart from the obvious conclusion that the higher the $\mathrm{DE}$, the greater the cariogenic potential of the glucose polymers, the findings suggest that re-formulating foods with the glucose syrups and maltodextrins used in this work may not be a satisfactory way of trying to reduce their cariogenic potential in man.

\section{References}

Bibby BG (1990) Food and the Teeth. New York, NY: Vantage Press Inc.

British Nutrition Foundation (1994) Briefing Paper on Starchy Foods in the Diet. London: BNF.

British Nutrition Foundation (1999) Oral Health - Diet and Other Factors [U Arens, editor]. London: Elsevier.

Brudevold F, Goulet D, Attarzadeh F \& Tehrani A (1988) Demineralization potential of different concentrations of gelatinized wheat starch. Caries Research 22, 204-209.

Department of Health (1989) Dietary Sugars and Human Disease. Report on Health and Social Subjects no. 37. Panel on Dietary Sugars, Committee on Medical Aspects of Food Policy. London: H.M. Stationery Office.

Edgar WM \& Dodds MW (1985) The effect of sweeteners on acid production in plaque. International Dental Journal 35, 18-22.

Fry AJ \& Grenby TH (1972) The effects of reduced sugar intake on the formation and composition of dental plaque in a group of men in the Antarctic. Archives of Oral Biology 17, 873-882. 
Govindasamy S, Campanella OH \& Oates CG (1997) The singlescrew extruder as a bioreactor for sago starch hydrolysis. Food Chemistry 60, 1-11.

Grenby TH (1972) The effect of glucose syrup on dental caries in the rat. Caries Research 6, 52-59.

Grenby TH (1997) Summary of the dental effects of starch. International Journal of Food Sciences and Nutrition 48, 229234.

Grenby TH \& Hutchinson JB (1969) The effects of diets containing sucrose, glucose or fructose on experimental dental caries in two strains of rats. Archives of Oral Biology 14, 373380.

Grenby TH \& Leer CJ (1974) Reduction in smooth-surface caries and fat accumulation in rats when sucrose in the drinking-water is replaced by glucose syrup. Caries Research 8, 368-372.

Grenby TH \& Mistry M (1995) Precise control of the frequency and amount of food provided for small laboratory animals by a new electronic metering technique, used to evaluate the cariogenic potential of chocolate. Caries Research 29, 418-423.

Grenby TH, Powell JM \& Gleeson MJ (1974) Effects of sweets made with and without sucrose on the dental plaque, and the correlation between the extent of plaque and human dental caries experience. Archives of Oral Biology 19, 217-224.
Moynihan PJ, Gould MEL, Huntley N \& Thorman S (1996a) Effect of glucose polymers in water, milk and a milk substitute on plaque $\mathrm{pH}$ in vitro. International Journal of Paediatric Dentistry 6, 19-24.

Moynihan PJ, Wright WG \& Walton AG (1996b) A comparison of the relative acidogenic potential of infant milk and soya infant formula: a plaque $\mathrm{pH}$ study. International Journal of Paediatric Dentistry 6, 177-181.

Rugg-Gunn AJ (1993) Nutrition and Dental Health. Oxford: Oxford University Press.

Russell RRB, Aduse-Opoken J, Sutcliffe IC, Tao L \& Ferretti J (1992) A binding protein-dependent transport system in Streptococcus mutans reponsible for multiple sugar metabolism. Journal of Biological Chemistry 267, 4631-4637.

Steinberg LM, Odulosa F \& Mandel ID (1996) Effect of sucralose in coffee on plaque $\mathrm{pH}$ in human subjects. Caries Research $\mathbf{3 0}$, 138-142.

Tao L, Sutcliffe IC, Russell RRB \& Ferretti JJ (1993) Cloning and expression of the multiple sugar metabolism [msm] operon of Streptococcus mutans in heterologous streptococcal hosts. Infection and Immunity 61, 1121-1125.

Yudkin J (1972) Pure White and Deadly. London: Davis-Pointer Ltd. 